\title{
The Involvement of Students in Social Network Sites Affects Their Learning
}

\author{
https://doi.org/10.3991/ijet.v14i13.10453 \\ Elda Tartari $(\bowtie)$, \\ University of Aleksandër Moisiu, Durrës, Albania \\ eldatartari@gmail.com \\ Alban Tartari \\ University of Tirana, Tiranë, Albania \\ Dilina Beshiri \\ University of Aleksandër Moisiu, Durrës, Albania
}

\begin{abstract}
The issue taken in consideration for this study is related to the extensive involvement of children in social media web pages and especially Facebook's social network. The purpose of this study is to explore the relationship between the level of engagement of pupils in social network sites and their performance of academic achievement. The methods used in the study are secondary data review and quantity methods. The population of this survey is school pupils between 10 to 15 years old. The sample was 1323 pupils surveyed in this study, selected at random from elementary and secondary schools. The data analysis focuses primarily in regressive models of the logistic binary. The study findings revealed a high level of pupils' involvement in social networks and mainly on Facebook's social network. It was also shown that the social network Facebook has a negative impact on the learning objectives of pupils who have opened an address compared to others who don't have an address in this network. Modern technologies are developing rapidly and the relationship between teachers, parents and pupils must function effectively through continuous communication on the effects of social network sites on their learning process.
\end{abstract}

Keywords-Pupils, Social network sites, Facebook, involvement, academic process

\section{Introduction}

In the past years, social network sites (SNSs) have gained extraordinary popularity. They are perfect examples of technological platforms that support social communications. These web pages are virtual communities offering a real-time approach, communication synchronicity, a possibility to post and share pictures, videos, and work that is original and creative. These web pages are very attractive and alluring for children and teenagers. SNSs offer a wide range of possibilities and choices for entertainment that teenagers prefer and are constantly seeking. 
Rudd et al., [1] suggested that social interactions and social mobility are possible through building of webs that entice communication, cohesion and learning. There are some social network sites, where individuals have created their online profiles to keep in contact socially with each other. In the last years, Facebook is at the top of social media options. Launched by Mark Zuckerberg in 2004, Facebook is followed by QZone, Google+, Linkedin, Instagram, and Twitter. Teenagers engage in social media using ways that contribute to their identity developments that were previously unthought-of. A study conducted in 2011, involving several EU countries and 25142 children between 6 and 16 years old, show that $59 \%$ of these age group have a social media account [2]. Another report by Livingstone et al. showed that social media is crowded especially in the Netherlands (80\%), Lithuania (76\%) and Denmark (75\%), less so in Romania (46\%), Turkey (49\%) and Germany (51\%) [3]. According to various studies conducted in the recent years the number of pre-teenagers and teenagers that use these web pages has increased dramatically. Even in Albania social networks are very populated and various issues have been observed. The problem that this study deals with has the impact of social networks in teaching process. The aim of the study is to explore the relationship between the level of inclusion of students in social networking sites in terms of performance achievement. To achieve this goal, research questions have been set forth: What is the level of involvement of pre-adolescent and adolescents aged 10-15 in social networks? What is the relationship between Facebook social networking and teaching preparation? Does the inclusion of pupils in social networks affect learning outcomes?

\section{Literature Review}

In 1984, Alexander Astin proposed his theory of students' inclusion known as theory of Student Involvement [4] [5]. The student involvement is defined as "the amount of physical and psychological energy the student dedicates to the academic experience" [6].

According to Astin, the theory of student involvement is based on five basic assumptions:

- Involvement refers to invested physical and psychological energies;

- Involvement is continuous (some students are more involved than others and students are individually involved in activities, at differing levels);

- Involvement has quantitative and qualitative aspects;

- Academic performance and student involvement in an academic program is directly proportional to quality and quantity of students of involvement in the program;

- The effectiveness of each academic practice is related to its ability to increase student involvement.

Astin emphasized that students achieve their academic goals because of the time and efforts dedicated to activities designed to achieve these goals. If the student spends a considerable amount of time not for studies but, for family and social activities, then this would reduce the amount of time dedicated to reach their academic goals. 
Junco [7] based his studies on Astin (1984) five basic assumptions of theory of involvement and analyzed students' involvement and time spent on Facebook in more details, as shown below:

- Involvement consists of the invested physical and psychological energy. Many studies support the fact that students invest a high proportion of their psychological energy on Facebook.

- Involvement happens to become continuous. Some spent more time on Facebook compared to others, and some don't use social media at all.

- Involvement has quantitative and qualitative aspects. Students may spent a long time on Facebook (the quantitative aspect) and can engage in a variety of activities offered by the platform (the qualitative aspect).

- The degree of learning and development of students in the academic program is directly correlated with the quantity and quality of students' involvement in the program. It is plausible that social media usage connects students with the real world in a more tangible way.

- The effectiveness of each academic practice is directly correlated with the practice's ability to increase students' involvement. If Facebook increases students' involvement, then it can be used as an educational tool to improve academic performance.

In the social networking context, the term "student involvement" refers to the time and effort students invest in educationally-relevant activities, both in-class and out-ofclass. These activities include participating in learning activities, assigning tasks, sharing school supplies and experiences, and collaborating and interacting with peers and schools [8]. Studies conducted by Heiberger \& Harper [4] found a direct correlation between social network sites usage and student involvement. Many studies suggest that social networking sites have the potential to radically change the academic system, and augment students' motivation for better engaging in the learning process instead of remaining passive in the classroom [9]. In his research study, Mason [10] stated that social networking sites have enough capacity to offer a proper "official" education that matches the social context of learning and promotes students critical thinking. Many researchers suggest that students use new ways to learn by utilizing social media and the teacher must constantly be on the loop regarding these new platforms [11] [12]. According to Jenkins, SNSs integrate social media in their mix and can help adolescent collect and analyze study materials, theoretically.

Dalsgaard [13] argued that social networking sites are ideal to support an interactive and constructive learning approach. For many years, theoreticians have proved that computer networks have potential to offer rich socio-cultural platforms, especially for learning foreign languages [14]). SNSs support the learning of foreign languages while learning through observing. Students gain confidence and become members of a community that encourages them to learn within that community and be self-taught [15]. Various researches show evidence of Facebook's effect on the learning process for children, teenagers, and young adults. Studies showed that Facebook has a positive effect when it is used as a resource and pedagogical tool that can potentially support everyone to enhance creativity, social interaction, communication skills, social spirit, social iden- 
tity, and to promote online ethical behavior. At the same time it is able to support students' needs, emotional side, experiences and characteristics [16]. The usage and participation on these networks in one way or the other could affect students in their studies. This is as a result of nature of the usage and how these students participate on these networks. Although social networks comes with a lot of positives such as improvement in reading skills and writing, the ability of the student not to discern and use it properly could affect his or her studies and could result in lower grades [17].

Despite the positive influence that social networks, like Facebook, have on the academic process, there are many other studies that reflect their downsides. According to Pempek et al., students and pupils have become active users of social network sites and consider it an important daily routine [18]. Students are motivated to use Facebook for lengthy periods of time as they need to be continuously connected. As soon as students increase time spent on Facebook, their grades are directly influenced [19]. During a conference, Karpinski's findings attracted attention, when he stated that students who use Facebook had a lower GPA than the ones that didn't use it. Junco \& Cotten showed that if students fixate after their online identities, academic objectives may fall behind and be negatively influenced [5]. Meanwhile, Junco [7] in his studies found that time spent on Facebook was directly proportional with the time spent for preparing homework, but was negatively correlated with results mapped to measure student involvement. According to Naqshbandi et al., the mediating role of Facebook usage was established only in the relationships of academic performance with extraversion, agreeableness and loneliness [20] . Result from the study of Abdulahi et al., shows that social network sites such as Facebook affect the scholars of Asia Pacific University. Time spent on social network sites is shown to negatively impact academic performance. As time spent on social networking sites increases, the academic performance of the students is seen to deteriorate [21].

Gok, T. reported in his study that the usage of social networking sites has negative impacts on students' studying, performance, and habit [22]. The study of Mensah and Nizam concluded that social media platforms have a significant impact on students' academic performance in Malaysia tertiary institution [23]. This is because time management plays an essential role in determining the success or failure of an individual. Thus, students who lack time management can easily fall prey to the negative impact on the performance of students. Unfortunately, it was found in Asiedu and Nasir Koranteng [24] that valuable time that could have been used to study by the students is wasted on social media sites. This shows that so much time is spent on social media sites by students at the expense of their academic work. Perception of school performance is influenced by the reasons for using social networking (0.13), effects of social networking $(-0.16)$, and learning attitude from using social networking $(0.11)$, [25]. Results of Liu, Kirschner and Karpinski indicated a significant negative relationship between SNS-use and academic performance. Moreover, they found that the relationship of SNS-use and GPA was more strongly negative in females and college student [26]. Furthermore in his study Chiungjung Huang [27] concluded a weighted mean correlation between use of social network sites and academic achievement is $=-0.07$. The mean correlation between SNS use and academic achievement was small and negative. 


\section{$3 \quad$ Methodology}

This is a transversal study that gathered data using the quantitative method. It describes and analyses the usage of social network, especially Facebook effect on pupils aged 10-15 years old and the effect it has on their studying process and doing homework.

The paper aims to test the links between the conceptual model variables taken in the study to better understand the role of pupils in social networks against pupils who are not involved in social networks.

\subsection{Research procedure}

The population sample analyzed in this study is from pupils between 10 to 15 years old in Albania. There are 1323 pupils engaged in the study. The study sample was selected randomly from the student list of 11 schools from 5 major cities (Tirana, Shkodra, Durrës, Vlora, and Korça). A lower number of pupils younger than 10 years-old were involved (178 pupils) and a higher number from the 14 years-old (284 pupils). More specifically: $13.9 \%$ (183 pupils) were 11 years-old; $14 \%$ (186 pupils) were 12 yearsold; $18.2 \%$ (240 pupils) were 13 years-old and $19.1 \%$ (252 pupils) were 15 years-old. The focus of the study was concentrated in the cities of Tirana, Shkoder, Durres, Vlore, Korce for some reasons. First of all, cities have been chosen in a good way because according to the Institute of Statistics, they have the highest number of people in the country. Secondly, according to the Electronic and Postal Communications Authority have the highest penetration rate for broadband access by fixed network by districts and thirdly these cities lie in different geographic positions. The city of Shkodra is located in the northwestern position of Albania, the city of Tirana is located in the center of Albania, the city of Durres is located in the west of Albania, the city of Vlora is located in the southwest of Albania and the city of Korca is located in the Southeast of Albania.

\subsection{Research tool}

The data analyzed in this study were collected from research questions designed as a research instrument that involved pupils going to elementary and middle school (which goes until grade 9). The questionnaire created for this study considered the fact that these pupils spent a great amount of time in social networks. SNSs and Facebook especially have attracted the attention of teenagers and have become an active component of their daily routines and social interaction and activities. From this perspective, this questionnaire considers Facebook as an important social element that affects the learning process. In order to evaluate Facebook usage activity, two dichotomy questions have been used. They are open-ended questions, and Likert scale questions to derive the frequency and agreement with the questions presented. Testing and retesting of the questionnaire was evaluated in a sub-sample of 150 pupils. The questionnaire was readministered to these 150 pupils with a 2 -week time difference from administering the first questionnaire. Pearson correlation coefficient resulted at $\mathrm{r}=0.75$, a value higher 
than 0.7 (the allowed normative) showing consistency of the questionnaire. The pupil questionnaires involved in the pilot phase were later excluded from the sample selection because their responses would reflect the preliminary recognition of the questionnaire. This pilot test served to improve the questionnaire regarding possible observations and inaccuracies based on relevant statistical formulas.

After data was collected, it was analyzed using statistical package IBM SPSS version 16.0. The results were interpreted based on a descriptive and statistical analysis and according to the research questions.

\section{Data Analysis}

\subsection{The usage of social network Facebook among pupils in the age group of 10- 15 years}

The result showed that from 1323 surveyed pupils, 893 (67.7\%) of them had a Facebook account, 426 (32.3\%) of them did not have one, and 4 of them had not answered the question. During the analysis of the given answers, of the ones who did not have a Facebook account, a majority of them had profiles in other social networks like Instagram, WhatsApp, and Viber. They declared that these platforms are easier and faster to use with their friends.

Pupils were asked on the time spent learning and doing homework. 878 pupils answered this question: 126 (14.4\%) of them spent less than one hour, $344(39.2 \%)$ spent 2 hours, $274(31.2 \%)$ spent 3 hours and 134 (15.3\%) spent more than 4 hours. The correlation between the question that showed the amount of time spent on FB and the time spent studying, using Gamma test, showed negative and weak result, but that was statistically significant nonetheless $(r=-0.15 ; \mathrm{p}<0.05)$. This assessment shows that an increase in time spent on FB, there is a decrease in time available for studying affecting, as a result, grades and academic performance that require focus and time to complete.

\subsection{Regressive analysis}

The analysis conducted on data collected from the questionnaire proceeds by utilizing a regressive model understand the impact of inclusion of pupils in social networks in learning outcomes by sharing with pupils that are not involved. Since the collected information is primaril y qualitative in nature, we will focus our analysis on regressive logistical models. The study is interested to analyze social network usage by pupils; thus, we will take as dependent variable the question: "Have you opened a FB account?" This variable takes two values: Yes or No. Consequently, the analysis focuses precisely on a regressive model of the logistic binary. A group of variables served as independent variables, achieving the best model, the results of which are reflected below.

Model Results: There are 1323 people (pupils) included in the model. 
Table 1. Case Processing Summary

\begin{tabular}{|l|l|c|c|}
\hline C Unweighted Cases A & \multicolumn{1}{|c|}{ Number } & Number & Percent \\
\hline Selected cases c & Included in Analysis & 1323 & 99.7 \\
\hline \multirow{5}{*}{} & Missing Cases & 4 & 0.3 \\
\cline { 2 - 4 } & Total & 1323 & 100 \\
\hline & Unselected cases & 0 & .0 \\
\cline { 2 - 4 } & Total & 1323 & 100 \\
\hline
\end{tabular}

Table 2 shows the options included in the model. In our case we have considered two values:

- 0 for people who don't have a FB account

- 1 for people who have a FB account

Table 2. Dependent Variable Encoding

\begin{tabular}{|l|c|}
\hline \multicolumn{1}{|c|}{ Original Value } & Internal Value \\
\hline No & 0 \\
\hline Yes & 1 \\
\hline
\end{tabular}

Table 3 depicts the number of pupils who answered each question. Four of the surveyed pupils have not answered the question. In this case we have real-valued, we don't have complex-valued variables, and therefore they are marked as zero. The table doesn't display crucial information, but we can later reference it to observe real-valued variables and complex-valued ones.

Table 3. 1Classification Table

\begin{tabular}{|c|l|c|c|c|c|}
\hline \multicolumn{2}{|c|}{ Observed cases } & \multicolumn{2}{|c|}{ Have you opened a FB account? } & \multirow{2}{*}{ Percentage } \\
\cline { 4 - 6 } \multicolumn{2}{|c|}{} & Yes & No & \\
\hline \multirow{4}{*}{ Step 0 0 } & 893 & 0 & 100.00 \\
\cline { 2 - 6 } & Have you had a FB account? & No & 426 & 0 & .0 \\
\cline { 2 - 6 } & General Percentage & & & & 67.8 \\
\hline
\end{tabular}

a. Constant is included in the model.

b. The cut value is .500

Table 4 shows whether there is an important statistical difference between pupils who answered yes and those who answered no, and we notice a statistically important difference. If the number of "Yes" and "No" were close in value, then Wald test would take a lower value and p-value (in the table) would certainly be higher than 0.05 . If this were true, then there wouldn't be a significant difference between these two groups. The table shows $\operatorname{Exp} \beta$ value. This value is important as it shows the probability that the pupil doesn't have a FB account $(426 / 893=0.474)$, also noted with $1-0.474$ to identify a pupil's probability of not having a FB account.

Table 4. Variables in the Equation

\begin{tabular}{|c|c|c|c|c|c|c|c|}
\hline & & B & S.E. & Wald & df & Sig. & $\operatorname{Exp(B)}$ \\
\hline Step 0 & Constant & -.746 & .059 & 160.680 & 1 & .000 & .474 \\
\hline
\end{tabular}


The table below shows variable testing which will be included in the model. The depicted variables are statistically significant and will be included in the model.

Table 5. Variables excluded from the equation

\begin{tabular}{|l|l|l|c|c|c|}
\hline & & Score & df & Sig. \\
\hline Step 0 & Variables & How much time do you spend studying & 782.124 & 1 & .000 \\
\hline & $\begin{array}{l}\text { Do you think FB prevents you from finishing your home- } \\
\text { work? }\end{array}$ & 785.348 & 1 & .000 \\
\hline & Are you involved in extra-curricular activities? & 887.532 & 1 & .000 \\
\hline & General statistics & 1107.876 & 3 & .000 \\
\hline
\end{tabular}

Table 6 shows Omnibus test results and available possibilities to evaluate the selected model. Results show that the model is statistically significant and can be used to evaluate.

Table 6. Omnibus Tests of Model Coefficients

\begin{tabular}{|c|c|c|c|c|}
\hline & & Chi-square & Df & Sig. \\
\hline Step 1 & Step & 1431.939 & 3 & .000 \\
\hline & Block & 1431.939 & 3 & .000 \\
\hline & Model & 1431.939 & 3 & .000 \\
\hline
\end{tabular}

Table 7 shows the model summary. The table presents value "-2 Log likelihood" which is similar to $\chi 2$ (Chi-square) distribution from the previous table. It is important to explain the squared multiple correlation R2 from Nagelkerke test, which is similar to R2 used in quantitative models to indicate the explanation of the model. According to Cox \& Snell, the basic measure is also R2 but, since it takes values lower than 1, then implementing R2 as used in Nagelkerke test proves challenging. These values show that our model has an explanation rate of $92.4 \%$.

Table 7. Model Summary

\begin{tabular}{|c|c|c|c|}
\hline Step & $\mathbf{- 2}$ Log likelihood & Cox \& Snell R Square & Nagelkerke R Square \\
\hline 1 & $231.490 \mathrm{a}$ & .661 & .924 \\
\hline
\end{tabular}

a. Estimation terminated at iteration number 9 because parameter estimates changed by less than .001 .

Hosmer-Lemeshow test is an analysis to further reassure the model used in this study. The test is utilized when assessing data collected from questionnaires and comparing expected-probability and outcome-probability rates of a given event. The test follows a $\chi^{2}$ distribution and the model is fitting if the test is statistically significant, thus taking a value higher than 0.05 of $\mathrm{p}$. Our test takes a value of 0.061 that shows that our model is fit and has $95 \%$ reliability. Therefore, considering the information we can rely on the model to make conclusions. 
Table 8. Hosmer and Lemeshow Test

\begin{tabular}{|c|c|c|c|}
\hline Step & Chi-square & Df & Sig. \\
\hline 1 & 12.032 & 6 & .061 \\
\hline
\end{tabular}

The last table shows the coefficients of the model. Coefficient interpretation is similar to the one used in quantitative models. From the analysis of answers to these questions we can conclude that there exists an indirect correlation between dependent variables and independent variables. Thus, we observe that there is a negative correlation between time spent on Facebook and doing homework, and that Facebook has a negative impact on preparing for and engaging in extra-curricular activities.

Table 9. Variables in the Equation

\begin{tabular}{|l|l|c|c|c|c|c|c|}
\hline \multicolumn{2}{|l|}{} & B & S.E. & Wald & df & Sig. & Exp(B) \\
\hline Step $1^{\text {a }}$ & $\begin{array}{l}\text { How much time do you spent } \\
\text { doing homework? }\end{array}$ & -1.068 & .245 & 18.984 & 1 & .000 & .344 \\
\hline & $\begin{array}{l}\text { Do you think FB prevents you } \\
\text { from doing your homework? }\end{array}$ & -.974 & .321 & 9.191 & 1 & .002 & .377 \\
\hline & $\begin{array}{l}\text { Are you engaged in extra-curric- } \\
\text { ular activites? }\end{array}$ & -3.321 & .576 & 33.297 & 1 & .000 & .036 \\
\hline & Constant & 3.827 & .331 & $\begin{array}{c}133.59 \\
2\end{array}$ & 1 & .000 & 45.919 \\
\hline
\end{tabular}

Variable(s) entered on step 1.

Variable interpretation pertaining to a logistical model is different from quantitative models that use multivariable. In these models $\beta_{\mathrm{i}}$ values explain the connection between independent and dependent variables. In order to interpret the effects of variables in the

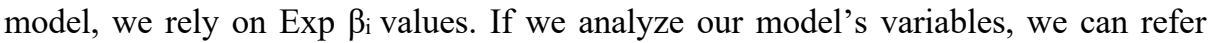
specifically to first question: "How much time do you spent doing homework?" The individual who has a Facebook account is 0.344 less able to prepare homework. If we take the other question into consideration: "Do you think Facebook prevents you from doing your homework?" then the individual who has a Facebook account is 0.377 less able to understand that social network involvement hinders his/her from doing homework. And regarding the last question: "Are you engaged in extra-curricular activities?" then the result show that the individual who has a Facebook account is 0.036 less able to engage in extra-curricular activities. The table shows that all our model's variables are statistically significant since all sig values are lower than 0.05 .

Variable interpretation pertaining to a logistical model is different from quantitative models that use multivariable. Logistical models are used to understand the relation between independent and dependent variables, and we depend on values in order to interpret model's variable effects. 


\section{Discussion}

\subsection{The level of pre-adolescent and adolescent's involvement of 10-15 year old's in social networks}

A plethora of modern technologies allows children to be part of SNSs. Social network sites are important social platforms that have penetrated our daily routines with a tremendous speed in order to facilitate communication [28]. This phenomenon has influenced children in the age group of 10-15 years old, who were also subject of this survey. The result showed that $67.7 \%$ among them use Facebook and the ones that are not active on Facebook admit that they use other platforms like Whats App, Instagram and Viber. This massive involvement of children in social networks includes urban areas like Tirana, Shkodra, Durrës, Vlora, Korça and disregards gender differences between girls and boys. The usage rate of SNSs in this age group is on the average higher when compared with the same age-group in 2010. Studies conducted in 25 developed countries like Italy, Turkey, Cypress, Denmark, Austria, Portugal, Romania, Ireland, Estonia, Bulgaria, Hungary, Poland, France, Belgium, Czech Republic, Lithuania, Spain, Ukraine, Norway, the Netherlands, Finland, Sweden, Germany, Greece and Slovakia showed that $59 \%$ of adolescent and preadolescent aged 9-16 years old had a profile in social media [2]. A rate similar to the one from 2014 data where $68 \%$ of this age-group used social media in Belgium, Denmark, Italy, Ireland, Portugal, Romania and Ukraine according to Net Children Go Mobile [3].

\subsection{Relationship between inclusion in Facebook social network and learning outcomes.}

The correlation between the question that showed the amount of time spent on FB and the time spent studying, using Gamma test, showed negative and weak result, but that was statistically significant nonetheless $(r=-0.15 ; \mathrm{p}<0.05)$. This assessment shows that an increase in time spent on FB, there is a decrease in time available for studying affecting, as a result, grades and academic performance that require focus and time to complete. This finding is supported from studies conducted by Liu, Kirschner and Karpinski [26] who demonstrated in their results a significant negative relationship between SNS-use and academic performance. Also, this result is supported by Huang, Chiungjung [27]. The latter in his study made it evident the mean correlation between SNS use and academic achievement was small and negative. [5]

\subsection{Impact on learning outcomes of pupil's inclusion in social networks.}

Studying and doing homework require the necessary amount of time and concentration. The study showed that of the surveyed pupils, $57 \%(\mathrm{~N}=502)$ of them check Facebook while they are doing homework, 34.8\% check Facebook more rarely, 12.8\% of them check it several times, $4 \%$ of them check it often and $5.5 \%$ of the surveyed pupils check Facebook very often. This widespread involvement negatively affects academic 
performance by reducing study time and focusing pupils on the performance of teaching tasks. These findings are supported by Junco \& Cotten [8] who admitted that pupils' fixation after their online identities has a negative effect on them as well as Astin (1984) who emphasizes that pupils achieve their study goals by concentrating and dedicating time to activities that are designed to help them achieve these goals. If the pupil is spending considerable time in non-academic activities, like doing social and family activities, then this reduces the amount of time available to achieve their academic goals. Also this finding supports in the same face value the study of Asiedu \& Nasir Koranteng [24] that so much time is spent on social media sites by students at the expense of their academic work.

The regressive analysis used for the study showed that pupils who have a Facebook account are 0.344 less able to prepare their homework compared to pupils who don't have a FB account. The individual who has a Facebook account is 0.377 less able to understand that $\mathrm{FB}$ obstructs the process of homework and the individual who has a Facebook account is 0.036 less able to engage in extra-curricular activities. Referring to these results, we say that Facebook plays a negative role in accomplishing teaching tasks and academic performance. This finding is supported by researcher Gok who reported that the usage of social networking sites on students' studying time, performance, and habit has negative impacts [22].

Given the high percentage of those who check Facebook while doing homework, the correlation and analyses of our model and results, we can conclude that Facebook plays a negative role. It hinders the process of studying and it distracts pupils while doing homework. Facebook prevents school pupils from studying and finishing their homework.

\subsection{Limitation}

The accomplishment of this study contains some limitations that the applicant is aware of and should be made aware before considering the interpretation of the results.

- Targeted population is that of 9-year schools in the cities of Tirana, Shkodra, Durres, Vlora and Korça, excluding students of the same age group in other towns and villages.

- The lack of financial means led the study to focus only on districts with the highest penetration of broadband access.

- Lack of studies in this area in our country results in a lack of comparison of findings to reflect the evolution of the internally studied phenomenon.

\section{Conclusion and Recommendations}

Inclusion in social networks of pre-adolescents and adolescents of 10 to 15 year olds in Albania is considered high where 67.7\% declared that they use Facebook and those who declared that they did not use Facebook, use Instagram and other communication 
apps like Viber and WhatsApp. The number of users among this age-group is considered high since their time spent online must be monitored.

There is a negative relationship $(r=-0.15 ; \mathrm{p}<0.05)$ between the time of inclusion in the Facebook social network and the time for the preparation of the lesson which means that with the increase of the time spent in the FB, the time to stay is reduced; this also affects the reduction of learning outcomes.

Pupils that have opened a Facebook account are 0.344 less able to prepare their homework compared to pupils that don't have a Facebook account. The pupil that has an active Facebook account is 0.377 less able to understand that their account prevents them from finishing their homework, and furthermore, those that have an account on Facebook have a 0.036 lower chance to engage in extra-curricular activities. As a result, Facebook has a negative effect and prevents school pupils from achieving their academic goals. Those pupils that have an active Facebook are negatively affected compared to those pupils that don't use Facebook and don't have an opened account.

Regarding the fact of being involved in the social networking network of the surveyed social group and the social networking impact of the teaching process, this begs the need for schools and families to coordinate and manage their online involvement but especially their activity on social network sites. It is necessary for parents and teachers to stay informed and be constantly on the loop about their children's online involvement, since it has an impact on this group-age's psycho-social development and academic achievements.

\section{$7 \quad$ References}

[1] Rudd, T., Sutch, D., \& Facer, K., (2006). "Towards new learning networks". Retrieved from https://www.nfer.ac.uk/publications/FUTL56/FUTL56.pdf.

[2] Livingstone, Sonia and Haddon, Leslie and Görzig, Anke and Ólafsson, Kjartan. (2011). "Risks and safety on the internet: the perspective of European children: full findings and policy implications from the EU Kids Online survey of 9-16 year olds and their parents in 25 countries", EU Kids Online, London, UK. https://doi.org/10.41 $\underline{35 / 978144627305014533936}$

[3] Livingstone S., Haddon Görzig A. and Ólafsson K., with members of the EU Kids Online network., (2014) "Risks and safety on the internet. The perspective of European children.," https://www.evernote.com/shard/s244/res/9945631c-fc41-403a-885b-b38c002a8aaf/. https://doi.org/10.4135/978144627305014533936

[4] Heiberger, G., \& Harper, R., (2008). Have you Facebooked Astin lately? Using technology to increase student involvement. In I. R. (Eds.), Using emerging technologies to enhance student engagemen., San Francisc: New directions for student service (pp. 19-35). https://doi.org/10.1002/ss.293

[5] Junco, R., \& Cotten, S., (2012). "No A 4 U: The relationship between multitasking and academic performance," Computers \& Education,, Vols. 59(2), pp. 505-514. https://doi.org/10.1016/j.compedu.2011.12.023

[6] A. W. Astin, (1984)."Student involvement: a developmental theory for higher education.," Journal of College Student Development, Vols. 25(4), , pp. 297-308. 
[7] R. Junco, (2011). "The relationship between frequency of Facebook use, participation in Facebook activities, and student engagement.," Computers \& Education, p. https://doi.org/10.1016/j.compedu.2011.08.004

[8] Abdulsalam Alhazmi \& Azizah Abdul Rahman, (2014) "A Framework for student engagement in social networking sites:," in Pacific Asia Conference on Information Systems, https://pdfs.semanticscholar.org/ddda/59d770508a3a152c141671c5d97586353b3e.pdf.

[9] S. Ziegler, (2007) "The (mis)education of Generation M. Learning,," Media and Technology, vol. 32 , no. no. 1, pp. $69-81$.

[10] R. Mason, (2006). "Learning Technologies for Adult Continuing Education.," Studies in Continuing Education, vol. 28, no. 2, pp. 121-133. https://doi.org/10.1 $\underline{080 / 01580370600751039}$

[11] Ito, M., Baumer, S., Bittanti, M., boyd, d., Cody, R., \& Herr-Stephenson, B., (2009). Hanging out, messing around, and geeking out: Kids living and earning with new media., Cambridge: MA: MIT Press. https://doi.org/10.7551/mitpress/8402.001.0001

[12] H. Jenkins, (2006). Confronting the challenges of participatory culture: Media education for the 21st century., Chicago: The John D. and CatherineT. MacArthur Foundation. https://doi.org/10.7551/mitpress/8435.001.0001

[13] C. Dalsgaard, (2008). Social networking sites: Transparency in online education. Paper presented at EUNIS Congress., Denmark: University of Aarhus, http://eunis.dk/ papers/p41.pdf.

[14] Harrison, M and Thomas, M., (2009). "Identity in online communities: Social networking sites and language learning.," International Journal of Emerging Technologies and Society , vol. vol. 7, no. no. 2, pp. 109-124.

[15] Ryberg, T. and Christiansen, E., (2008)."Community and social network sites as technology enhanced learning environments.," Technology, Pedagogy and Education, vol. vol. 17, no. no.3, pp. 207 - 219. https://doi.org/10.1080/14759390802383801

[16] Geordy G. Reid \& Wanda Boyer, (2013). "Social Network Sites and Young Adolescent Identity.," Childhood Education, vol. 89, no. 4, pp. 243-253, https://doi.org/10.10 $\underline{\text { 80/00094056.2013.815554 }}$

[17] Mingle, J., Adams, M., Adjej, E.A., (2016). "A Comparative Analysis of Social Media Usage and Academic Performance in Public and Private Senior High Schools.," Journal of Education and Practice, vol. Vol.7, no. No.7, , pp. 13-22.

[18] Pempek, T., Yermolayeva, Y., \& Calvert, S., (2009). "College student's social networking experiences on Facebook.," Journal of Applied Developmental Psychology, vol. 30, no. 3, pp. 227-238. https://doi.org/10.1016/j.appdev.2008.12.010

[19] Kirschner, P. A., \& Karpinski, A. C., (2010). "Facebook and academic performance.," Computers in Human Behavior, vol. 26, p. 1237-1245. https://doi.org/10.1 $\underline{016 / j . c h b .2010 .03 .024}$

Naqshbandi,Muzamil M., Sulaiman Ainin, Noor Ismawati Jaafar, Nor Liyana Mohd Shuib,( 2017). "To Facebook or to Face book? An investigation of how academic performance of different personalities is affected through the intervention of Facebook usage.," Computers in Human Behavior, vol. Volume 77, pp. 148-157. https://doi.org/10.1 016/j.chb.2017.05.012

[20] Abdulahi, A., Samadi, B., Gharleghi, B., (2014). "A Study on the Negative Effects of Social Networking Sites Such as Facebook among Asia Pacific University Scholars in Malaysia.," International Journal of Business and Social Science. , Vols. Vol. 5, no. No. 10.

[21] Gok, T., (2016). "The effects of social networking sites on students' studying and habits.,," International Journal of Research in Education and Science (IJRES), vol. 2 , no. 1, pp. 8593. https://doi.org/10.21890/ijres.10682 
[22] Mensah, S.O., Nizam, I., (2016). "The impact of social media on students' academic performance- A case of malaysia tertiary institution.," International Journal of Education. , vol. Vol. 1 , no. No.1, pp. 14-21.

[23] Asiedu \& Nasir Koranteng, (2017). "Influence of social networking sites on students' academic and social lives: The Ghanaian Perspective.," Library Philosophy and Practice (ejournal)., p. 1535. http://digitalcommons.unl.edu/libphilprac/1535

[24] Masood Badri, Ali Al Nuaimi, Yang Guang, Asma Al Rashedi, (2017). " School performance, social networking effects, and learning of school children: Evidence of reciprocal relationships in Abu Dhabi.," Telematics and Informatics. , vol. Volume 34, no. Issue 8, pp. 1433-1444. https://doi.org/10.1016/j.tele.2017.06.006

[25] Liu, D., Kirschner, P. A., Karpinski, A. C., (2017). "A meta-analysis of the relationship of academic performance and social network site use among adolescents and young adults," Computers in Human Behavior., vol. Volume 77, pp. 148-157. https://doi.org/10.10 16/j.chb.2017.08.039

[26] C. Huang, (2018). "Socila network site use and academic achievement: A meta- analysis.," Computers \& Education., vol. Volume 119., pp. 76-83. https://doi.org/10.1016 j.compedu.2017.12.010

[27] Correa, T., Hinsley, A.W., \& de Zuniga, H. G., (2010). "Who interacts on the web? The intersection of users' personality and social media use.," Computers in Human Behavior", vol. 26, no. 2 , pp. 247-253. https://doi.org/10.1016/j.chb.2009.09.003

\section{Authors}

Dr. Elda Tartari is a full-time lecturer at the Department of Pedagogy at the Aleksandër Moisiu University of Durrës and she is a part time lecturer at the Department of Pedagogy and Psychology at the Tirana University. She holds a Ph.D. in Education Science from Tirana University. She has authored and co-authored many publications in peer reviewed journals at regional, national and international conferences, workshops and symposiums. Email: eldatartari@gmail.com.

Dr. Alban Tartari has been working for 19 years in the field of active journalism, public relations and marketing, and lecturing in the universities. Graduated from the University of Ankara - Turkey, Journalism Branch. He holds a Master of Arts degree in Political Science and International Relations, and a Ph.D. degree on journalism and communication from Tirana State University. Actually, he is a full-time lecturer and researcher at the University of Tirana, Department of Journalism and Communication. Email: albantartari@gmail.com

Dr. Dilina Beshiri is a full-time lecturer at the Department of Pedagogy at Aleksandër Moisiu University of Durrës and has over 10 years of experience as a full-time lecturer. She holds a Ph.D. in Education Sciences from the University of Bari, Italy. She has published more than 20 publications in peer reviewed journal articles and many published articles in national and international conferences. Email: dilina_b@hotmail.com

Article submitted 2019-03-11. Resubmitted 2019-04-19. Final acceptance 2019-04-21. Final version published as submitted by the authors. 